Manuscript Number: JCLEPRO-D-19-05319R2

Title: Rapid sintering of weathered municipal solid waste incinerator bottom ash and rice husk for lightweight aggregate manufacturing and product properties

Article Type: Original article

Keywords: Lightweight aggregate; weathered incinerator bottom ash; residual agricultural biomass; rice husk

Corresponding Author: Dr. Josep Maria Ma. Chimenos, Ph.D.

Corresponding Author's Institution: University of Barcelona

First Author: Jessica Giro-Paloma

Order of Authors: Jessica Giro-Paloma; Jofre Mañosa; Àlex MaldonadoAlameda; Margarida J Quina; Josep Maria Ma. Chimenos, Ph.D.

Abstract: This study assessed the technical feasibility of formulating lightweight aggregates (LWA) from municipal solid waste incinerator bottom ash (IBA) and residual biomass. Weathered IBA (WIBA) particles larger than $8 \mathrm{~mm}$ contain a mixture of calcium-rich compounds and other silicates mainly composed of glass and synthetic and natural ceramics, with low contents of heavy metals and soluble salts. Unfired LWA were formulated with the particle size fraction of WIBA larger than $8 \mathrm{~mm}$ and rice husk (RH) used as the bloating agent. Rapid sintering of the unfired spherical pellets at $1,100^{\circ} \mathrm{C}$ for $5 \mathrm{~min}$ produced some cohesive sintered LWA, whose porosity, apparent particle density, water absorption, and compressive strength directly correlated with the percentage of $\mathrm{RH}$ added. The fired LWA formulated with 5 wt. $\%$ of RH showed the highest bloating index (115\%) and porosity (53\%) and the lowest apparent particle density $(0.61 \mathrm{Mg} \cdot \mathrm{m}-3)$ and compressive strength (1.4 MPa). The addition of more than 5 wt. ㅇ of RH increased the internal temperature of the sintered aggregates and decreased the viscosity of the molten glassy materials, resulting in the collapse of the inner structure. Consequently the porosity decreased and the apparent density of the particles increased, thereby shrinking the volume of the fired LWA. According to the standard leaching test (EN 12457-4), both the unfired precursor and the sintered aggregates showed concentrations of heavy metals and metalloids in the leachates that were well below the safety limits established for their reuse as secondary materials. 


\title{
Rapid sintering of weathered municipal solid waste incinerator bottom ash and rice husk for lightweight aggregate manufacturing and product properties
}

\author{
J. Giro-Paloma ${ }^{\mathrm{a}}$, J. Mañosa ${ }^{\mathrm{a}}$, A. Maldonado-Alameda ${ }^{\mathrm{a}}$, M.J. Quina ${ }^{\mathrm{b}}$, J.M. Chimenos ${ }^{\mathrm{a},{ }^{*}}$ \\ ${ }^{a}$ Departament de Ciència de Materials i Química Física, Universitat de Barcelona, C/ Martí i Franquès 1, 08028, \\ Barcelona, Spain. \\ ${ }^{\mathrm{b}}$ CIEPQPF- Chemical Process Engineering and Forest Products Research Centre, Department of Chemical \\ Engineering, University of Coimbra, Rua Sílvio Lima, Coimbra, 3030-790, Portugal
}

* Corresponding author e-mail: chimenos@ub.edu 


\section{Ref. No.: JCLEPRO-D-19-05319R1}

Title: Rapid sintering of weathered municipal solid waste incinerator bottom ash and rice husk for lightweight aggregate manufacturing and product properties

Answers to the reviewer:

First of all, the authors would like to thank the Editor and Reviewers for all the corrections and suggestions. We have considered them to enhance the quality of our manuscript. The responses to the reviewer's comments and questions are presented below. We hope we have answered all the questions and clarified all the issues.

\section{Answers to Reviewer \#2}

1. Suggested title: Rapid sintering of weathered municipal solid waste incinerator bottom ash and rice husk for lightweight aggregate manufacturing and product properties

Done. The title has been changed according to the suggestion.

2. A notation list is necessary.

A section with the nomenclature has been added before to the introduction.

3. The broken reference linkage in Page 12, Line 30 has still not been deleted.

The linkage has been deleted.

\section{Answers to Reviewer \#3:}

There is a remaining linkage error on page 12, line 30. Such broken links are very common after managing the manuscript for submission, and only after printing (for example, pdf printing) it can be noticed. I recommend the pdf printing and double checking before the submission to avoid inconveniences.

Done. The pdf file has been checked before the submission. 


\title{
Rapid sintering of weathered municipal solid waste incinerator bottom ash and rice husk for lightweight aggregate manufacturing and product properties
}

\author{
J. Giro-Paloma ${ }^{\mathrm{a}}$, J. Mañosa ${ }^{\mathrm{a}}$, A. Maldonado-Alameda ${ }^{\mathrm{a}}$, M.J. Quina ${ }^{\mathrm{b}}$, J.M. Chimenos $^{\mathrm{a},{ }^{*}}$ \\ ${ }^{a}$ Departament de Ciència de Materials i Química Física, Universitat de Barcelona, C/ Martí i Franquès 1, 08028, Barcelona, Spain. \\ ${ }^{\mathrm{b}}$ CIEPQPF- Chemical Process Engineering and Forest Products Research Centre, Department of Chemical Engineering, University of \\ Coimbra, Rua Sílvio Lima, Coimbra, 3030-790, Portugal \\ * Corresponding author e-mail: chimenos@ub.edu
}




\begin{abstract}
This study assessed the technical feasibility of formulating lightweight aggregates (LWA) from municipal solid waste incinerator bottom ash (IBA) and residual biomass. Weathered IBA (WIBA) particles larger than $8 \mathrm{~mm}$ contain a mixture of calcium-rich compounds and other silicates mainly composed of glass and synthetic and natural ceramics, with low contents of heavy metals and soluble salts. Unfired LWA were formulated with the particle size fraction of WIBA larger than $8 \mathrm{~mm}$ and rice husk $(\mathrm{RH})$ used as the bloating agent. Rapid sintering of the unfired spherical pellets at $1,100^{\circ} \mathrm{C}$ for 5 min produced some cohesive sintered LWA, whose porosity, apparent particle density, water absorption, and compressive strength directly correlated with the percentage of RH added. The fired LWA formulated with 5 wt.\% of RH showed the highest bloating index (115\%) and porosity (53\%) and the lowest apparent particle density $\left(0.61 \mathrm{Mg} \cdot \mathrm{m}^{-3}\right)$ and compressive strength $(1.4 \mathrm{MPa})$. The addition of more than $5 \mathrm{wt} . \%$ of RH increased the internal temperature of the sintered aggregates and decreased the viscosity of the molten glassy materials, resulting in the collapse of the inner structure. Consequently the porosity decreased and the apparent density of the particles increased, thereby shrinking the volume of the fired LWA. According to the standard leaching test (EN 12457-4), both the unfired precursor and the sintered aggregates showed concentrations of heavy metals and metalloids in the leachates that were well below the safety limits established for their reuse as secondary materials.
\end{abstract}

Keywords: Lightweight aggregate; weathered incinerator bottom ash; residual agricultural biomass; rice husk. 


\title{
Nomenclature
}

\author{
$A P C \quad$ air pollution control fly ash \\ BI bloating index \\ DTG derivative of the thermogravimetric \\ IBA incinerator bottom ash \\ ICP-MS inductively coupled plasma mass spectrometry \\ LOI loss on ignition \\ LWA lightweight aggregates \\ MSW municipal solid waste \\ $R H \quad$ rice husk \\ RHA rice husk ash \\ TGA thermogravimetric analysis \\ WIBA weathered incinerator bottom ash \\ $X R D \quad$ X-Ray diffraction \\ $X R F \quad \mathrm{X}$-ray fluorescence \\ $\sigma_{c} \quad$ compressive strength
}

\section{Introduction}

Due to the growing amount of residual waste in Europe, the Waste Framework Directive (2008/98/EC), amended by Directive (EU) 2018/851, encourages to apply the waste hierarchy to provide viable alternatives for managing waste and efficiently use resources to move towards a lowcarbon economy. This includes the development of sustainable alternatives that can reuse different kinds of waste by formulating them into secondary materials. 
Incineration of municipal solid waste (MSW) in waste-to-energy plants is expected to increase all over the world due to increased consumption and the limited use of landfills (Cabrera et al., 2016). Although the incineration process considerably reduces the mass and volume of MSW by about $75 \%$ and $90 \%$, respectively, it still produces significant amounts of ash, namely incinerator bottom ash (IBA) and air pollution control (APC) fly ash (Wiles, 1995). IBA is the most significant waste from MSWI, accounting for $85-95 \%$ of the solid remaining from combustion (Izquierdo et al., 2002). It is classified as non-hazardous waste (EWC 190112) and can be revalorized as secondary raw material after weathering for 2-3 months to immobilize heavy metals (Chimenos et al., 1999; Grosso et al., 2011).

IBA is a highly heterogeneous material, mainly composed of glass, synthetic and natural ceramics, magnetic and paramagnetic metals, and a small percentage of unburned organic matter (Chimenos et al., 1999). Glass (primary and secondary glass) is the major component (40-60\%), while both synthetic ceramics and mineral compounds account for more than $30 \%$ (del ValleZermeño et al., 2017).. However, the distribution of these materials is not homogeneous and depends on the particle size. While the finer fractions contain most of the heavy metals and soluble salts, the coarser fractions are rich in glass cullet and synthetic ceramics, like pieces of bricks, porcelain or tiles. Accordingly, IBA is regarded as a mixture of calcium-rich compounds and other silicates enriched in iron and sodium (Freyssinet et al., 2002), with appropriate chemical and physical characteristics for reuse as secondary materials in civil engineering and construction (Verbinnen et al., 2016). Though, the reuse of IBA as secondary material may be limited by its high levels of heavy metals, chlorides and sulphates, which mainly occur in IBA particle size fraction lower than $4 \mathrm{~mm}$ and can be mobilized in the aqueous phase by leaching process (Chimenos et al., 2003; del ValleZermeño et al., 2014).

Sintering at high temperatures has been shown to significantly reduce the release of heavy metals, which are incorporated or embedded into the neo-formed crystalline or vitreous phases (Bourtsalas et 
al., 2015; Schabbach et al., 2012; Verbinnen et al., 2016). Although the leaching potential appreciably decreases as the processing temperature increases, the sintering of IBA at temperatures of around $1,100{ }^{\circ} \mathrm{C}$, to obtain lightweight aggregates (LWA) for instance, reduces the release of heavy metals when compared to the original unbound material (Cheeseman et al., 2005, 2003).

LWA, which have very low densities $\left(0.5-2.0 \mathrm{~g} \cdot \mathrm{cm}^{-3}\right)$, are being increasingly used to formulate lightweight concrete, lightweight geotechnical fills, insulation products, soil engineering, hydroculture, drainage, roof gardens, and filters, among others (Cheeseman et al., 2005; Quina et al., 2014). In addition, LWA display acoustic insulation and fire resistance and have a low thermal conductivity (Qiao et al., 2008). Besides naturally occurring low-density materials (e.g. volcanic cinders or pumice), LWA can be produced by thermal processes using raw materials with expansive properties, such as clayey materials. LWA can also be manufactured from industrial by-products such as fly ash from coal power plants, sewage sludge or expanded blast-slag (Cheeseman et al., 2005; González-Corrochano et al., 2012, 2009; Kourti and Cheeseman, 2010). Furthermore, the use of MSWI waste, mainly APC fly ash, to produce LWA has also been reported (Hwang et al., 2012; Quina et al., 2014; Tan et al., 2012). Thus, because of its high glass content (i.e. low softening point material) and the possibility to encapsulate the heavy metals contained, an attractive way to reuse IBA could be as a resource in the formulation of LWA (Cheeseman et al., 2005).

To achieve an appropriately expanded material, two conditions are necessary: the presence of substances that release gases at high temperatures and a plastic phase with adequate viscosity to trap the evolved gases. In this regard and to increase the porosity of the material to provide a lower density, biomass could be added since it decomposes during sintering to produce high volumes of gases, e.g., oil (Quina et al., 2014; Quina et al., 2014b), thereby facilitating the bloating before sintering. Regarding the possibility of adding biomass, rice husk (RH) could be used to increase porosity (Chiang et al., 2009), providing amorphous-Si to improve the cohesive forces between particles during sintering. $\mathrm{RH}$ is a major agricultural by-product comprising about $40 \%$ cellulose, 
$30 \%$ lignin and 20\% silica (Posi et al., 2013). After combustion, the rice husk ash, RHA, is mainly composed of silica (>90\%), most of which is amorphous, depending on the temperature as well as the duration of the calcination process (Chandrasekhar et al., 2006; Rashid and Frantz, 1992).

In this study, the particle size fraction greater than $8 \mathrm{~mm}$ of IBA was used as a matrix and RH as the biomass component to produce lightweight aggregates, by means of a rapid sintering process. Accordingly, the aim of this work was to formulate and produce (ball-shaped pellets) LWA from two different by-products. The physicochemical and mechanical properties of the LWA produced were evaluated, as well as their environmental impact due to the leaching process with water.

\section{Materials and methods}

\subsection{Incinerator bottom ash and rice husk}

IBA was collected from a waste-to-energy plant located in Tarragona (Spain). The feed stream treated in this incineration plant is mainly composed of household rubbish with a small input from commercial sources. Approximately 32,000 tons per year of IBA are produced in the incineration plant and further treated in a conditioned/revalorization process for the recovery of valuable metals. The IBA is then stockpiled in the open for at least three months to ensure the immobilization of heavy metals by weathering.

Around $100 \mathrm{~kg}$ of weathered IBA (WIBA) was taken from various stockpiles. After homogenization by quartering method (Komnitsas, 2011) and drying, WIBA was screened through an 8 -mm sieve, with particles larger than $8 \mathrm{~mm}$ (34 wt.\%) taken for use in this study and later quartered by a riffle-type sample splitter. After removing the metal components with a metal magnet $(\mathrm{Nd} ; 0.485 \mathrm{~T})$, subsamples were dried overnight at $105^{\circ} \mathrm{C}$ and dry ball milled with a Jaw Crusher BB $50(\mathrm{RETSCH})$ for 2 to $3 \mathrm{~h}$ before being passed through an $80-\mu \mathrm{m}$ sieve to produce a fine homogeneous powder suitable for sintering. 
The rice husk $(\mathrm{RH})$ used in this study was supplied by the agricultural cooperative of the Delta de l'Ebre (Tarragona, Spain). After homogenization, $\mathrm{RH}$ subsamples were dried overnight at $105^{\circ} \mathrm{C}$ and milled in a rotary cutting mill before being passed through an $80-\mu \mathrm{m}$ sieve to produce a fine homogeneous powder suitable for use as an additive in the formulation of unfired spherical pellets.

The characterization of WIBA and RH involved X-ray fluorescence (XRF) using a Philips Panalytical PW 2400 sequential X-ray fluorescence spectrometer. X-Ray diffraction (XRD) pattern, using a Bragg-Brentano Siemens D-500 powder diffractometer device with $\mathrm{CuK} \alpha$ radiation and processing the data by the X'Pert Highscore software, and thermogravimetric analysis (TGA) and the derivative of the TGA curve (DTG) in air atmosphere, using a TA Instruments SDT Q600, a heating rate of $10^{\circ} \mathrm{C} \mathrm{min}^{-1}$ from 30 to $1,200^{\circ} \mathrm{C}$ and a flow rate of gas of $50 \mathrm{~mL} \mathrm{~min}{ }^{-1}$.

\subsection{Production of lightweight aggregates}

According to the designed proportions (Table 1), the resulting fine powders of WIBA and RH were thoroughly mixed to ensure homogeneity. Subsequently, a controlled amount of water (20$25 \%$ ) was added to the mixture to give consistency and workability that would allow the formation of unfired spherical pellets with a diameter of 10-12 mm. Fifteen to eighteen "green" spherical pellets were handmade for each formulation to determine their chemical, physical and mechanical parameters. The molded pellets were dried at $105^{\circ} \mathrm{C}$ in an oven for $24 \mathrm{~h}$ prior to firing in an electric laboratory furnace. The dried pellets were sintered in the furnace over pre-drilled holes $(\varnothing=8 \mathrm{~mm})$ on a rigid ceramic fiber board (Kaowool) $(20 \mathrm{~mm} \mathrm{x} 80 \mathrm{~mm} \times 150 \mathrm{~mm}$ ) at a target temperature of $1,100{ }^{\circ} \mathrm{C}$ for $5 \mathrm{~min}$, before being quenched in air. This temperature was selected because sintering pre-tests performed at lower temperatures (e.g. $1,050{ }^{\circ} \mathrm{C}$ ) resulted in weak and poorly cohesive aggregates lacking in consistency, which were considered to be non-sintered. Moreover, sintering at temperatures above $1,100{ }^{\circ} \mathrm{C}$ (or firing times greater than $5 \mathrm{~min}$ ) resulted in melted particles without a regular shape and/or high density, thus producing a collapsed structure. Therefore, $1,100{ }^{\circ} \mathrm{C}$ and 5 
min were the sintering conditions used for all the formulations (Table 1). Although the sintering temperature $\left(1,100{ }^{\circ} \mathrm{C}\right)$ is above the working point of soda-lime-silica glass $\left(995^{\circ} \mathrm{C} ; 10^{4} \mathrm{P}\right)$, the rapid sintering process $(5 \mathrm{~min})$ requires a higher temperature and lower viscosity to allow for the cohesion of the matrix and the formation of pores. Accordingly, the study only focused on the effects of adding different amounts of RH on the physical and mechanical properties of the sintered LWA.

\subsection{Characterization of sintered LWA}

The different formulations were characterized to determine their physical, mechanical and chemical properties, which would then be used to determine the optimal formulation (WIBA/RH, wt./wt.\%) for obtaining LWA. In this regard, XRD analysis was performed. Furthermore, weight loss after the firing process at $1,100^{\circ} \mathrm{C}$, dry density (apparent specific gravity) and water absorption according to the EN 1097-6:2000 standard, as well as shrinking (or enlargement) and the compressive strength of the sintered handmade spherical balls were determined. Based on the mean diameters of the unfired and sintered spherical balls (measured by using a digital caliper at 4-5 positions each) before and after sintering, the bloating index (BI) was determined with equation Eq. 1,

$$
B I(\%)=\frac{V_{i}-V_{f}}{V_{i}} \times 100
$$

where $V_{f}$ is the estimated volume $\left(\mathrm{cm}^{3}\right)$ after sintering and $V_{i}$ is the estimated volume before sintering.

The compressive strength $\left(\sigma_{\mathrm{c}}\right)$ of the individual sintered LWA was measured using a universal testing machine Zwick Roell Zmart-PRO, equipped with a $10 \mathrm{kN}$ load cell, using a loading rate of 2 $\mathrm{mm} \cdot \mathrm{min}^{-1}$. The sintered spherical pellets were inserted between two parallel rigid surfaces, while the load to fracture was analyzed. The compressive strength of all the formulations was compared with Eq. 2 (Cheeseman et al., 2005), 
where $\mathrm{X}$ is the distance between the loading points (the diameter of the sphere) $(\mathrm{mm})$ and $\mathrm{P}_{\mathrm{c}}$ the fracture load $(\mathrm{N})$.

Finally, the standard leaching test EN 12457-4 was undertaken to determine the potential release of heavy metals and metalloids from WIBA and LWA. The leaching procedure involves the extraction of the solids with deionized water at the $\mathrm{L} / \mathrm{S}$ ratio of $10 \mathrm{~L} \cdot \mathrm{kg}^{-1}$ for $24 \mathrm{~h}$ under agitation. The liquid was separated with a $0.45 \mu \mathrm{m}$ pore membrane, and 15 elements were analyzed by inductively coupled plasma mass spectrometry (ICP-MS), Perkin Elmer Optima 3200 RL.

\section{Results and discussion}

\subsection{Characterization of WIBA and RH}

Table 2 shows the chemical composition of the fraction of WIBA larger than $8 \mathrm{~mm}$, which was determined by XRF. The major compounds were $\mathrm{SiO}_{2}$ and $\mathrm{CaO}$, likely related to the content of glass cullet and synthetic ceramics in the MSW. The contents of $\mathrm{Fe}_{2} \mathrm{O}_{3}$ and $\mathrm{Al}_{2} \mathrm{O}_{3}$ were also significant, with the former mainly related to the presence of unrecovered ferrous metals and the latter possibly from both non-ferrous metals and clay-based synthetic ceramics (del Valle-Zermeño et al., 2017). XRD spectra (not shown) allowed the identification of calcite $\mathrm{CaCO}_{3}$, quartz $\mathrm{SiO}_{2}$, hydroxylapatite $\mathrm{Ca}_{5}\left(\mathrm{PO}_{4}\right)_{3}(\mathrm{OH})$, dolomite $\mathrm{CaMg}\left(\mathrm{CO}_{3}\right)_{2}$, vaterite $\left(\mathrm{CaCO}_{3}\right)$, albite calcian $\left(\mathrm{Na}_{0.84} \mathrm{Ca}_{0.16}\right) \mathrm{Al}_{1.16} \mathrm{Si}_{2.84} \mathrm{O}_{8}$, Akermanite $\mathrm{Ca}_{2}\left(\mathrm{Mg}_{0.75} \mathrm{Al}_{0.25}\right)\left(\mathrm{Si}_{1.75} \mathrm{Al}_{0.25} \mathrm{O}_{7}\right)$, orthoclase $\mathrm{KAlSi}_{3} \mathrm{O}_{8}$, and calcium sulphate $\mathrm{Ca}\left(\mathrm{SO}_{4}\right)$ as major crystalline phases. However, given the high content of glass cullet in this size fraction, the highest content should be considered as corresponding to the amorphous phase.

TGA of WIBA (Fig. 1) indicates that the mass loss occurred in several steps, with a total decomposition of around 9\% denoting the presence of unburned organic matter (exothermic reaction), carbonates and other hydroxides and hydrated salts (endothermic reactions) decomposing 
with temperature. Accordingly, a high volume of gases was expected to contribute to the bloating before LWA sintering, while a large weight loss would increase porosity and reduce the densities of the sintered aggregates. Total weight loss $\left(8.92 \mathrm{wt} . \%\right.$ at $\left.1,000^{\circ} \mathrm{C}\right)$ is consistent with the results reported in Table $2\left(9.58 \mathrm{wt} \%\right.$ of LOI at $\left.1,000^{\circ} \mathrm{C}\right)$.

Regarding the RH thermal degradation, TGA and DTG curves are depicted in Fig. 2. An initial weight loss occurred below $100^{\circ} \mathrm{C}$, which was related to the vaporization of water because of the hydrophilic character of the lignocellulose fibers. The weight loss in the temperature range from 225 to $550^{\circ} \mathrm{C}$ was due to the combustion of hemicellulose, lignin, pectin and cellulose (Johar et al., 2012). TGA analysis revealed a total decomposition of around $76 \%$. On burning, the organic matter decomposed, generating a high volume of gases that again contributed to the bloating process and the increase in the porosity of the LWA samples, reducing the densities of the sintered aggregates.

According to the XRF and XRD characterization, the major compound in the residual ash of RH was silica $\left(\mathrm{SiO}_{2}\right.$, around $\left.95 \%\right)$, which remains in the amorphous form at combustion temperatures of up to $900^{\circ} \mathrm{C}$ (Blissett et al., 2017; Faé Gomes et al., 2016; Yeoh et al., 1979).

\subsection{Properties of LWA}

Six formulations were tested (Table 1) starting with unfired particles of 10-12 mm. As shown in Fig. 3, the sintered aggregates may exhibit bloating (enlargement of its diameter) or shrinking depending on the percentage of RH used in the formulation. Indeed, the weight loss of each unfired spherical pellet was determined after the sintering process to obtain their corresponding fired aggregates. Fig.4 depicts a good correlation $\left(\mathrm{R}^{2}=0.94\right)$ between weight loss and the percentage of $\mathrm{RH}$ used in the different formulations. However, neither the weight loss of the WIBA fraction (5.4 wt.\%; 0 wt.\% of RH) nor the weight loss of the RH (i.e. slope of the regression line; $\approx 60$ wt.\%) corresponded to the weight loss previously determined in the TGA of both sources (see Fig. 1 and 2). This could be a result of the incomplete combustion of both materials due to the rapid sintering 
process (e.g., the combustion of RH in anoxic conditions) or to the combination of some calcination products resulting in the formation of neo-formed mineral phases. Regarding the XRD analysis of the sintered LWA samples, wollastonite $\left(\mathrm{CaSiO}_{3}\right)$ and quartz $\left(\mathrm{SiO}_{2}\right)$ were the main crystalline phases detected for all the formulations studied, while the presence of carbonates or hydroxides (e.g. calcite) was not perceived. However, the highest content should be considered as corresponding to the vitreous phases.

During the firing process, the high volume of gases generated by the thermal decomposition of both WIBA and RH contributed to the bloating before sintering, thereby increasing porosity, with the weight loss reducing the densities of the sintered LWA.

Moreover, it is also important to note that the expanded sintered specimens showed two different layers (Fig. 5): the vitrified outer layer on the external surface, and the vitreous skeleton inner layer. Both the porosity and pore size, as well as the colors of the inner and outer layers, were different and varied with the percentage of RH added. Fired LWA formulated using only WIBA ( 0 wt.\% of RH; Fig. 5a) presented a homogeneous porous texture that consisted of small closed pores evenly distributed over all the sintered material. In this case, there were no major differences in the texture of the inner and outer layers, as well as in their pore sizes and color. The thermal decomposition of the carbonates and hydroxides in the WIBA $(>8 \mathrm{~mm})$, distributed homogeneously throughout the material, was sufficient to generate a large number of pores.

The addition of 2 to 5 wt.\% of RH (Fig. $5 \mathrm{~b}$ and $5 \mathrm{c}$, respectively) led to a sharp increase in the number of large pores in the inner layer, while the outer layer still showed tiny pores that were evenly distributed. In these cases ( 2 and $5 \mathrm{wt} . \%$ of $\mathrm{RH}$ ), the increase in the percentage of $\mathrm{RH}$ used also increased the pore size, both in the inner and outer layer. However, the addition of $10 \mathrm{wt} . \%$ of RH (Fig. 5d) produced a compact texture in the inner layer, while the largest pores were concentrated 
in the outer layer. Finally, the addition of $15 \mathrm{wt} . \%$ of $\mathrm{RH}$ (Fig. 5e) generated a compact vitreous structure with the smallest pore sizes, both in the inner and outer layer.

With the exception of the sintered LWA in the absence of $\mathrm{RH}(0 \mathrm{wt} . \%$ of $\mathrm{RH})$, the outer and inner layers showed noticeable differences in color, with the color gradually darkening with an increasing percentage of $\mathrm{RH}$ added. The darkening of the inner layer is attributable to the char particles generated during the anoxic combustion of the biomass (RH), while in the oxic conditions (outer layer) this combustion is complete and the dark color disappears.

Through a computer-based analysis (Image $\mathrm{J}^{\mathrm{TM}}$ processing program), the $2 \mathrm{D}$ cross-section images obtained by optical microscopy (e.g. Fig. 5a-e) were used to determine the porosity (Dullien, 1991) and distribution of pore sizes for each formulation of LWA. The resulting images were digitized directly from the microscope and the greyscale images were then thresholded to differentiate between the pore and solid spaces (i.e. the number of pore pixels), while the noise in the image was removed. As it is difficult to differentiate small pores in greyscale images, especially in samples with a darker inner layer, all pores smaller than $5 \mu \mathrm{m}$ were discarded during analysis. For all the formulations studied, the vast majority of pores were smaller than $50 \mu \mathrm{m}$ (Fig. 6a). However, with the addition of small percentages of RH (2 to $5 \mathrm{wt} . \%)$, the pore size increased significantly, increasing with the percentage of RH used and resulting in pores larger than $700 \mu \mathrm{m}$ (e.g., Fig. 5c). By contrast, with the addition of a higher percentage of RH (e.g. 10 to 15 wt.\% of RH), large pores did not form and most of them were smaller than those formulated without RH or with only a small percentage of RH (i.e. $\leq 5 \mathrm{wt} . \%$ of $\mathrm{RH})$. The highest percentage of large pores $(>350 \mu \mathrm{m})$ was observed in sintered aggregates formulated with $5 \mathrm{wt} . \%$ of $\mathrm{RH}$, while aggregates formulated with higher percentages of RH presented low number of large pores. Considering the area and sphericity factor of all the pores, calculated by an image computer-based analysis, porosity appeared to be a function of the percentage of the bloating agent used (Fig. 6b). However, due to the dark color of the inner layer of the fired LWA formulated with a higher percentage of RH (Fig. 5d and 5e), it is 
possible that the porosity determined in these specimens was actually greater than the measurement obtained. However, the porosity of LWA did not increase with the percentage of added RH, reaching a maximum value of 54\% when $5 \mathrm{wt} . \%$ of RH was utilized and then decreasing when the percentage of RH used was higher than $5 \mathrm{wt} . \%$.

Fig. 7 shows the bloating index, BI (\%), as a function of the percentage of RH (wt.\%) used, with negative values indicating bloating (enlargement) of the sintered LWA. In the absence of RH (0 wt.\% of RH), the sintering of WIBA particles larger than $8 \mathrm{~mm}$ caused a BI of approximately $26 \%$. In this case, the gases generated during decarbonation and dehydration by the thermal decomposition of the WIBA were sufficient to expand the sintered aggregates. The BI increased with the percentage of $\mathrm{RH}$, reaching a maximum when $5 \mathrm{wt} . \%$ of $\mathrm{RH}$ was used. The flue gases generated during the combustion of the biomass increased the bloating to up to $115 \%$ of the initial volume, with the glassy material reaching the pyroplastic state and the viscosity of the melted material is right to trap the released gases. In addition, gases generated from the RH had sufficient vapor pressure to increase the pore volume and expand the material (see Fig. 6).

The porous network of the aggregates began to collapse when the amount of RH was greater than $5 \mathrm{wt} . \%$. The inner structure collapsed and the sintered aggregates bloat less or even shrink when high percentages of RH were used, consequently leading to the production of dense granules. Indeed, LWA with 15 wt.\% of RH show shrinking compared to the unfired pellets. However, the BI was not affected by increasing the percentage of RH from 15 wt.\% (i.e. 20 wt.\% of RH). In these cases, it is possible that the inner temperature increases significantly due to the combustion of a large amount of biomass, decreasing the pyroplastic viscosity of the melted glassy material and increasing the cohesion between the WIBA particles. Consequently, the porosity and pore size decrease (see Fig. 5), with the pores becoming evenly distributed to produce aggregates with a higher density. 
The apparent particle density $\left(\mathrm{Mg} \cdot \mathrm{m}^{-3}\right)$ and water absorption (wt.\%) of the fired LWA were measured using the Archimedes principle, according to EN 1097-6:2000. Fig. 8 shows the effect of adding RH (wt.\%) on both physical properties. The apparent particle density of all the fired LWA formulated with WIBA (> $8 \mathrm{~mm}$ ) and RH (Fig. 8a) varied between 0.6 and $1.8 \mathrm{Mg} \cdot \mathrm{m}^{-3}$. As expected, particle density directly correlated with the porosity of the sintered LWA, with lower apparent density when the porosity was higher (Fig. 6b). Once again, the aggregates formulated with 5 wt.\% of RH had the lowest apparent particle density $\left(0.61 \mathrm{Mg} \cdot \mathrm{m}^{-3}\right)$. It is interesting to observe that the fired LWA formulated with a large amount of RH (> $15 \mathrm{wt} . \%)$ had a lower apparent particle density than those formulated without the RH. In these cases, the collapse of the inner structure caused the shrinking of the particles and increased the apparent particle density.

Fig. $8 \mathrm{~b}$ shows the water absorption of the fired LWA in relation to the amount of RH used. Water absorption increased linearly with the amount of bloating agent added, from $1.7 \mathrm{wt} \%$ of water for LWA formulated without RH to $16 \mathrm{wt} \%$ for particles formulated with $15 \mathrm{wt} . \%$ of RH. Since water absorption is directly related to open porosity, it is thought that a higher percentage of $\mathrm{RH}$ generates a higher percentage of pores in the outer (surface) layer during the rapid firing process. In this case, the slope of the estimated regression line was 0.92 . Hence, water absorption (wt.\%) can be thought of as equivalent to the percentage of $\mathrm{RH}$ (wt.\%) added as the bloating agent. All the formulations assessed in this study had lower water absorption than some commercial LWA described in the literature (Ayati et al., 2019; Quina et al., 2014), which is a very desirable physical property in the production of lightweight concrete.

Fig. 9 shows the effect of the percentage of $\mathrm{RH}$ used on compressive strength. The average compressive strength decreased from 6.6 MPa for $0 \mathrm{wt} . \%$ of $\mathrm{RH}$ to its minimum value of $1.4 \mathrm{MPa}$ for 5 wt.\% of RH. After this point, compressive strength increased slightly until reaching a plateau when the percentage of $\mathrm{RH}$ added was more than $10 \mathrm{wt} . \%$. This physical property is also significantly 
affected by porosity and the inner pore size. Thus, the greater the porosity and inner pore size is (i.e. lower density LWA), the lower the compressive strength.

\subsection{Leaching impact assessment}

Finally, to determine the potential environmental impact of formulating LWA with residual sources (i.e. WIBA $>8 \mathrm{~mm}$ ), the standard leaching test EN 12457-4 was performed. Table 3 shows the results of this test in relation to the percentage of $\mathrm{RH}$ added as the bloating agent. To carry out the leaching test the broken aggregates $(<10 \mathrm{~mm})$ from the mechanical compression tests were used. Table 3 also shows the results for WIBA particles as received and after ground into particles with diameters less than $80-\mu \mathrm{m}$ powder. The $\mathrm{pH}$ of the WIBA was above 9.0, controlled by the formation of calcium carbonate (Chimenos et al., 2003). After sintering, the $\mathrm{pH}$ fell to values close to 7.8 due to the decomposition of the carbonates and the incorporation of calcium into the siliceous matrix. Moreover, both the unfired and sintered aggregates released heavy metals and metalloids in the leachates well below the limits established for reuse as secondary materials. The small differences between the fired aggregates were more likely to be due to the heterogeneity of the WIBA than to the differences in the formulation of the unfired LWA. The release of As was slightly higher in the leachates from the sintered LWA than from those of the WIBA used as precursor, probably due to the decrease in $\mathrm{pH}$ and the leaching of the iron oxides hosting As in their lattice structure.

\section{Conclusions}

This study demonstrated the feasibility of obtaining lightweight aggregates from WIBA particle size fraction larger than $8 \mathrm{~mm}$ through a rapid sintering process, as a way to revalorizing this fraction of WIBA rich in vitreous materials. The addition of $\mathrm{RH}$ as a bloating agent increased the porosity and decreased the apparent particle density of the sintered LWA. However, while the use of small amounts of $\mathrm{RH}(<5 \mathrm{wt} . \%)$ resulted in the bloating of the aggregates during sintering, the addition of more than $10 \mathrm{wt} . \%$ of $\mathrm{RH}$ produced shrinking and generated denser aggregates than those obtained 
without RH. In this case, the combustion of the large quantities of RH considerably increased the temperature, reducing the viscosity of the molten vitreous phases and causing the collapse of the internal structure.

All the physical properties evaluated were directly related to the porosity of the sintered LWA, which in turn could be controlled by adding different amounts of RH. The compressive strength and water absorption of the LWA obtained in this study were similar to or better than those of the commercial LWA described in the literature, therefore increasing the usability of these LWA. Large porosity generates low weight and good thermal and acoustic insulation. Therefore, the addition of $\mathrm{RH}$ is a promising method for regulating the porosity of LWA formulated with WIBA (> $8 \mathrm{~mm}$ ).

The use of weathered IBA, in particular the fraction larger than $8 \mathrm{~mm}$ containing lower concentrations of soluble salts, heavy metals, and metalloids, decreases the polluting potential of the precursor. Moreover, the formation of the outer vitreous layer waterproofs the inner layer and decreases the permeability to water, thereby reducing the release of pollutants.

\section{Acknowledgments}

The work was partially funded by the Spanish Government (BIA2017-83912-C2-1-R) and by an STSM Grant from COST Action CA15115. The authors would like to acknowledge the Catalan Government for the quality accreditation given to the research group DIOPMA (2017 SGR 118). Authors also thank SIRUSA and VECSA for supplying the MSWI bottom ash and the cooperative of the Delta de l'Ebre for the rice husk. Mr Alex Maldonado-Alameda is grateful to the Government of Catalonia for the research grant FI-DGR 2017.

\section{References}

Ayati, B., Molineux, C., Newport, D., Cheeseman, C., 2019. Manufacture and performance of lightweight aggregate from waste drill cuttings. J. Clean. Prod. 208, 252-260. doi:https://doi.org/10.1016/j.jclepro.2018.10.134

Blissett, R., Sommerville, R., Rowson, N., Jones, J., Laughlin, B., 2017. Valorisation of rice husks using a TORBED® combustion process. Fuel Process. Technol. 159, 247-255. 
doi:10.1016/j.fuproc.2017.01.046

Bourtsalas, A., Vandeperre, L.J., Grimes, S.M., Themelis, N., Cheeseman, C.R., 2015. Production of pyroxene ceramics from the fine fraction of incinerator bottom ash. Waste Manag. 45, 217-225. doi:10.1016/j.wasman.2015.02.016

Cabrera, M., Galvin, A.P., Agrela, F., Beltran, M.G., Ayuso, J., 2016. Reduction of leaching impacts by applying biomass bottom ash and recycled mixed aggregates in structural layers of roads. Materials (Basel). 9, 1-21. doi:10.3390/ma9040228

Chandrasekhar, S., Pramada, P.N., Majeed, J., 2006. Effect of calcination temperature and heating rate on the optical properties and reactivity of rice husk ash. J. Mater. Sci. 41, 7926-7933. doi:10.1007/s10853-006-0859-0

Cheeseman, C.R., Makinde, A., Bethanis, S., 2005. Properties of lightweight aggregate produced by rapid sintering of incinerator bottom ash. Resour. Conserv. Recycl. 43, 147-162. doi:10.1016/j.resconrec.2004.05.004

Cheeseman, C.R., Monteiro Da Rocha, S., Sollars, C., Bethanis, S., Boccaccini, A.R., 2003. Ceramic processing of incinerator bottom ash. Waste Manag. 23, 907-916. doi:10.1016/S0956053X(03)00039-4

Chiang, K.-Y., Chou, P.-H., Hua, C.-R., Chien, K.-L., Cheeseman, C., 2009. Lightweight bricks manufactured from water treatment sludge and rice husks. J. Hazard. Mater. 171, 76-82. doi:10.1016/j.jhazmat.2009.05.144

Chimenos, J.., Segarra, M., Fernández, M.., Espiell, F., 1999. Characterization of the bottom ash in municipal solid waste incinerator. J. Hazard. Mater. 64, 211-222. doi:10.1016/S03043894(98)00246-5

Chimenos, J.M., Fernández, A.I., Miralles, L., Segarra, M., Espiell, F., 2003. Short-term natural weathering of MSWI bottom ash as a function of particle size. Waste Manag. 23, 887-895. doi:S0956- 053X(03)00074-6

del Valle-Zermeño, R., Chimenos, J.M., Giró-Paloma, J., Formosa, J., 2014. Use of weathered and fresh bottom ash mix layers as a subbase in road constructions: Environmental behavior enhancement by means of a retaining barrier. Chemosphere 117, 402-409. doi:10.1016/j.chemosphere.2014.07.095

del Valle-Zermeño, R., Gómez-Manrique, J., Giro-Paloma, J., Formosa, J., Chimenos, J.M., 2017. Material characterization of the MSWI bottom ash as a function of particle size. Effects of glass recycling over time. Sci. Total Environ. 581-582. doi:10.1016/j.scitotenv.2017.01.047

Dullien, F.A.L., 1991. Porous Media. Fluid Transport and Pore Structure. Academic Press, Inc., London.

Faé Gomes, G.M., Philipssen, C., Bard, E.K., Zen, L.D., De Souza, G., 2016. Rice husk bubbling fluidized bed combustion for amorphous silica synthesis. J. Environ. Chem. Eng. 4, 2278-2290. doi:10.1016/j.jece.2016.03.049

Freyssinet, P., Piantone, P., Azaroual, M., Itard, Y., Clozel-Leloup, B., Guyonnet, D., Baubron, J.C., 2002. Chemical changes and leachate mass balance of municipal solid waste bottom ash submitted to weathering. Waste Manag. 22, 159-172. 
González-Corrochano, B., Alonso-Azcárate, J., Rodas, M., 2012. Effect of thermal treatment on the retention of chemical elements in the structure of lightweight aggregates manufactured from contaminated mine soil and fly ash. Constr. Build. Mater. 35, 497-507. doi:10.1016/j.conbuildmat.2012.04.061

González-Corrochano, B., Alonso-Azcárate, J., Rodas, M., 2009. Characterization of lightweight aggregates manufactured from washing aggregate sludge and fly ash. Resour. Conserv. Recycl. 53, 571-581. doi:10.1016/j.resconrec.2009.04.008

Grosso, M., Biganzoli, L., Rigamonti, L., 2011. A quantitative estimate of potential aluminium recovery from incineration bottom ashes. Resour. Conserv. Recycl. 55, 1178-1184.

Hwang, C.-L., Bui, L.A.-T., Lin, K.-L., Lo, C.-T., 2012. Manufacture and performance of lightweight aggregate from municipal solid waste incinerator fly ash and reservoir sediment for self-consolidating lightweight concrete. Cem. Concr. Compos. 34, 1159-1166. doi:10.1016/j.cemconcomp.2012.07.004

Izquierdo, M., López-Soler, A., Ramonich, E. V, Barra, M., Querol, X., 2002. Characterisation of bottom ash from municipal solid waste incineration in Catalonia. J. Chem. Technol. Biotechnol. 77, 576-583.

Johar, N., Ahmad, I., Dufresne, A., 2012. Extraction, preparation and characterization of cellulose fibres and nanocrystals from rice husk. Ind. Crops Prod. 37, 93-99. doi:10.1016/j.indcrop.2011.12.016

Komnitsas, K.A., 2011. Potential of geopolymer technology towards green buildings and sustainable cities. Procedia Eng. 21, 1023-1032. doi:10.1016/j.proeng.2011.11.2108

Kourti, I., Cheeseman, C.R., 2010. Properties and microstructure of lightweight aggregate produced from lignite coal fly ash and recycled glass. Resour. Conserv. Recycl. 54, 769-775. doi:10.1016/j.resconrec.2009.12.006

Posi, P., Teerachanwit, C., Tanutong, C., Limkamoltip, S., Lertnimoolchai, S., Sata, V., Chindaprasirt, P., 2013. Lightweight geopolymer concrete containing aggregate from recycle lightweight block. Mater. Des. 52, 580-586. doi:10.1016/j.matdes.2013.06.001

Qiao, X.C., Ng, B.R., Tyrer, M., Poon, C.S., Cheeseman, C.R., 2008. Production of lightweight concrete using incinerator bottom ash. Constr. Build. Mater. 22, 473-480. doi:10.1016/j.conbuildmat.2006.11.013

Quina, M.J., Almeida, M.A., Santos, R., Bordado, J.M., Quinta-Ferreira, R.M., 2014. Compatibility analysis of municipal solid waste incineration residues and clay for producing lightweight aggregates. Appl. Clay Sci. 102, 71-80. doi:10.1016/j.clay.2014.10.016

Quina, M.J., Bordado, J.M., Quinta-Ferreira, R.M., 2014. Recycling of air pollution control residues from municipal solid waste incineration into lightweight aggregates. Waste Manag. 34, 430-8. doi:10.1016/j.wasman.2013.10.029

Rashid, R.A., Frantz, G.C., 1992. MSW Incinerator Ash as Aggregate in Concrete and Masonry. J. Mater. Civ. Eng. 4, 353-368. doi:10.1061/(ASCE)0899-1561(1992)4:4(353)

Schabbach, L.M., Andreola, F., Barbieri, L., Lancellotti, I., Karamanova, E., Ranguelov, B., Karamanov, A., 2012. Post-treated incinerator bottom ash as alternative raw material for ceramic manufacturing. J. Eur. Ceram. Soc. 32, 2843-2852. 
doi:10.1016/j.jeurceramsoc.2012.01.020

Tan, W., Wang, L., Huang, C., Liu, Y., Green, J.E., Newport, D., Green, T., 2012. Utilization of municipal solid waste incineration fly ash in lightweight aggregates. J. Cent. South Univ. 19, 835-841. doi:10.1007/s11771-012-1080-8

Verbinnen, B., Billen, P., Van Caneghem, J., Vandecasteele, C., 2016. Recycling of MSWI Bottom Ash: A Review of Chemical Barriers, Engineering Applications and Treatment Technologies. Waste and Biomass Valorization 1-14. doi:10.1007/s12649-016-9704-0

Wiles, C.C., 1995. Municipal solid waste combustion ash : State of the knowledge. J. Hazard. Mater. 3894, 20. doi:10.1016/0304-3894(95)00120-4

Yeoh, A.K., Bidin, R., Chong, C.N., Tay, C.Y., 1979. The relationship between temperature and duration of burning of rice-husk in the development of amorphous rice-husk ash silica, in: Proceedings of UNDP/ESCAP/ RCT, Follow-up Meeting on Rice-Husk Ash Cement. Alor Setar, Malaysia,. 
Table 1.- Formulation of unfired spherical pellets.

\begin{tabular}{lcccccc}
\hline & \multicolumn{6}{c}{ (wt.\% - wt. \%) } \\
\cline { 2 - 7 } WIBA - RH & $100-0$ & $98-2$ & $95-5$ & $90-10$ & $85-15$ & $80-20$ \\
\hline
\end{tabular}


Table 2.- Chemical composition of the WIBA fraction $>8 \mathrm{~mm}$ determined by XRF.

\begin{tabular}{lclc}
\hline Oxides & $\begin{array}{c}\text { wt. \% } \\
\text { (dry basis) }\end{array}$ & Oxides & $\begin{array}{c}\text { wt.\% } \\
\text { (dry basis) }\end{array}$ \\
\hline $\mathrm{SiO}_{2}$ & 53.15 & $\mathrm{~K}_{2} \mathrm{O}$ & 1.56 \\
$\mathrm{CaO}$ & 15.14 & $\mathrm{SO}_{3}$ & 0.87 \\
$\mathrm{Al}_{2} \mathrm{O}_{3}$ & 6.46 & $\mathrm{TiO}_{2}$ & 0.44 \\
$\mathrm{Na}_{2} \mathrm{O}$ & 5.43 & $\mathrm{P}_{2} \mathrm{O}_{5}$ & 0.41 \\
$\mathrm{Fe}_{2} \mathrm{O}_{3}$ & 4.28 & $\mathrm{MnO}$ & 0.07 \\
$\mathrm{MgO}$ & 2.01 & & \\
\hline $\mathrm{LOI}$ & 9.58 & & \\
\hline
\end{tabular}

${ }^{*}$ Loss on ignition at $1,000{ }^{\circ} \mathrm{C}$. 
Table 3.- Results from leaching test EN 12457-4.

1

2

3

4

5

6

7

8

9

10

11

12

13

14

15

16

17

18

19

20

21

22

23

24

25

26

27

28

29

30

31

32

33

34

35

36

37

38

39

40

41

42

43

44

45

46

47

48

49

50

51

52

53

54

55

56

57

58

59

60

61

62

63

64

65

\begin{tabular}{|c|c|c|c|c|c|c|}
\hline $\begin{array}{l}\text { WIBA >8 mm } \\
\text { (as received) }\end{array}$ & $\begin{array}{c}\text { WIBA }>8 \mathrm{~mm} \\
\quad(<80 \mu \mathrm{m})\end{array}$ & $\begin{array}{c}\text { LWA } \\
\text { 0 wt.\% RH }\end{array}$ & $\begin{array}{c}\text { LWA } \\
2 \text { wt. \% RH }\end{array}$ & $\begin{array}{c}\text { LWA } \\
5 \text { wt. \% RH }\end{array}$ & $\begin{array}{c}\text { LWA } \\
10 \text { wt. \% RH }\end{array}$ & $\begin{array}{c}\text { LWA } \\
15 \text { wt. \% } \\
\text { RH }\end{array}$ \\
\hline
\end{tabular}

\begin{tabular}{|c|c|c|c|c|c|c|c|c|}
\hline pH & 9.06 & 9.34 & 7.70 & 7.65 & 7.74 & 7.73 & 7.95 & \\
\hline \multicolumn{9}{|c|}{ Heavy Metals and Metalloids $\left(\mathrm{mg} \cdot \mathrm{kg}^{-1}\right)$} \\
\hline As & $<0.01$ & $<0.01$ & 0.07 & 0.11 & 0.17 & 0.27 & 0.27 & 1.00 \\
\hline $\mathbf{B a}$ & 0.04 & 0.21 & 0.14 & 0.18 & 0.11 & 0.09 & 0.11 & - \\
\hline Cd & $<0.01$ & $<0.01$ & $<0.01$ & $<0.01$ & $<0.01$ & $<0.01$ & $<0.01$ & 1.00 \\
\hline $\mathrm{Cr}$ & 0.10 & 0.13 & 0.62 & 0.64 & 0.29 & 0.15 & $<0.12$ & 5.00 \\
\hline $\mathbf{C u}$ & 0.36 & 0.72 & 0.04 & 0.05 & 0.09 & 0.07 & 0.05 & 20.0 \\
\hline $\mathbf{F e}$ & $<0.10$ & $<0.10$ & $<0.10$ & $<0.10$ & $<0.10$ & $<0.10$ & $<0.10$ & - \\
\hline Hg & $<0.05$ & $<0.05$ & $<0.05$ & $<0.05$ & $<0.05$ & $<0.05$ & $<0.05$ & 0.20 \\
\hline Mn & $<0.01$ & $<0.01$ & $<0.01$ & $<0.01$ & 0.01 & $<0.01$ & $<0.01$ & - \\
\hline Mo & 0.12 & 0.37 & 0.07 & 0.07 & 0.06 & 0.03 & 0.09 & - \\
\hline $\mathbf{N i}$ & $<0.02$ & $<0.02$ & $<0.02$ & $<0.02$ & $<0.02$ & $<0.02$ & $<0.02$ & 5.00 \\
\hline $\mathbf{P b}$ & $<0.01$ & $<0.01$ & $<0.01$ & $<0.01$ & 0.07 & 0.04 & 0.03 & 5.00 \\
\hline $\mathrm{Se}$ & $<0.10$ & $<0.10$ & $<0.10$ & $<0.10$ & $<0.10$ & $<0.10$ & $<0.10$ & - \\
\hline Sn & $<0.02$ & $<0.02$ & $<0.02$ & $<0.02$ & $<0.02$ & $<0.02$ & $<0.02$ & - \\
\hline $\mathbf{T e}$ & $<0.02$ & $<0.02$ & $<0.02$ & $<0.02$ & $<0.02$ & $<0.02$ & $<0.02$ & - \\
\hline Zn & $<0.10$ & $<0.10$ & $<0.10$ & $<0.10$ & $<0.10$ & $<0.10$ & $<0.10$ & 20.0 \\
\hline
\end{tabular}

Regulatory limit according to Catalan legislation (DOGC No. 2181; February, $15^{\text {th }} 1996$ ) for MSWI bottom ash reutilization. 


\section{Figure Caption}

Fig. 1. TGA and DTG of WIBA fraction $>8 \mathrm{~mm}$ in air atmosphere $\left(50 \mathrm{~mL} \cdot \mathrm{min}^{-1}\right)$ with a heating rate of $10^{\circ} \mathrm{C} \cdot \mathrm{min}^{-1}$ up to $1200^{\circ} \mathrm{C}$.

Fig. 2. TGA and DTG of RH in air atmosphere $(50 \mathrm{~mL} \cdot \mathrm{min}-1)$ with a heating rate of $10^{\circ} \mathrm{C} \cdot \mathrm{min}^{-1}$ up to $1200{ }^{\circ} \mathrm{C}$.

Fig. 3. Image of the unfired LWA samples and fired spherical lightweight aggregates (after the heating treatment). The expansion and shrinkage depending on the $\mathrm{RH}$ amount.

Fig. 4. Weight loss after the sintering process at $1100{ }^{\circ} \mathrm{C}$ for 5 min depending on $\mathrm{RH}$ percentage in the formulation of the unfired pellets.

Fig. 5. Optical images of fired LWA depending on the percentage of RH added as bloating agent. (a) 0 wt. $\%$, (b) 2 wt. $\%$, (c) 5 wt. $\%$, (d) 10 wt. $\%$ and (e) 15 wt. $\%$.

Fig. 6. (a) Pore size distribution and (b) porosity of fired LWA depending on the percentage of RH added as a bloating agent.

Fig. 7. Volume shrinkage depending on the percentage of RH (wt.\%) after the sintering process at $1100^{\circ} \mathrm{C}$ for $5 \mathrm{~min}$.

Fig. 8. (a) Apparent particle density and (b) water absorption of fired LWA depending on the percentage of RH added as a bloating agent.

Fig. 9. Compressive strength results for the sintered LWA based on the RH added. 
1

2
3

4

5

6

7

8

10

11

12

13

14

15

16

17

18

19

20

21

22

23

24

25

26

27

28

29

30

31

32

33

34

35

36

37

38

39

40

41

42

43

44

45

46

47

48

49

50

51

52

53

54

55

56

57

58

59

60

61

62

63

64

65

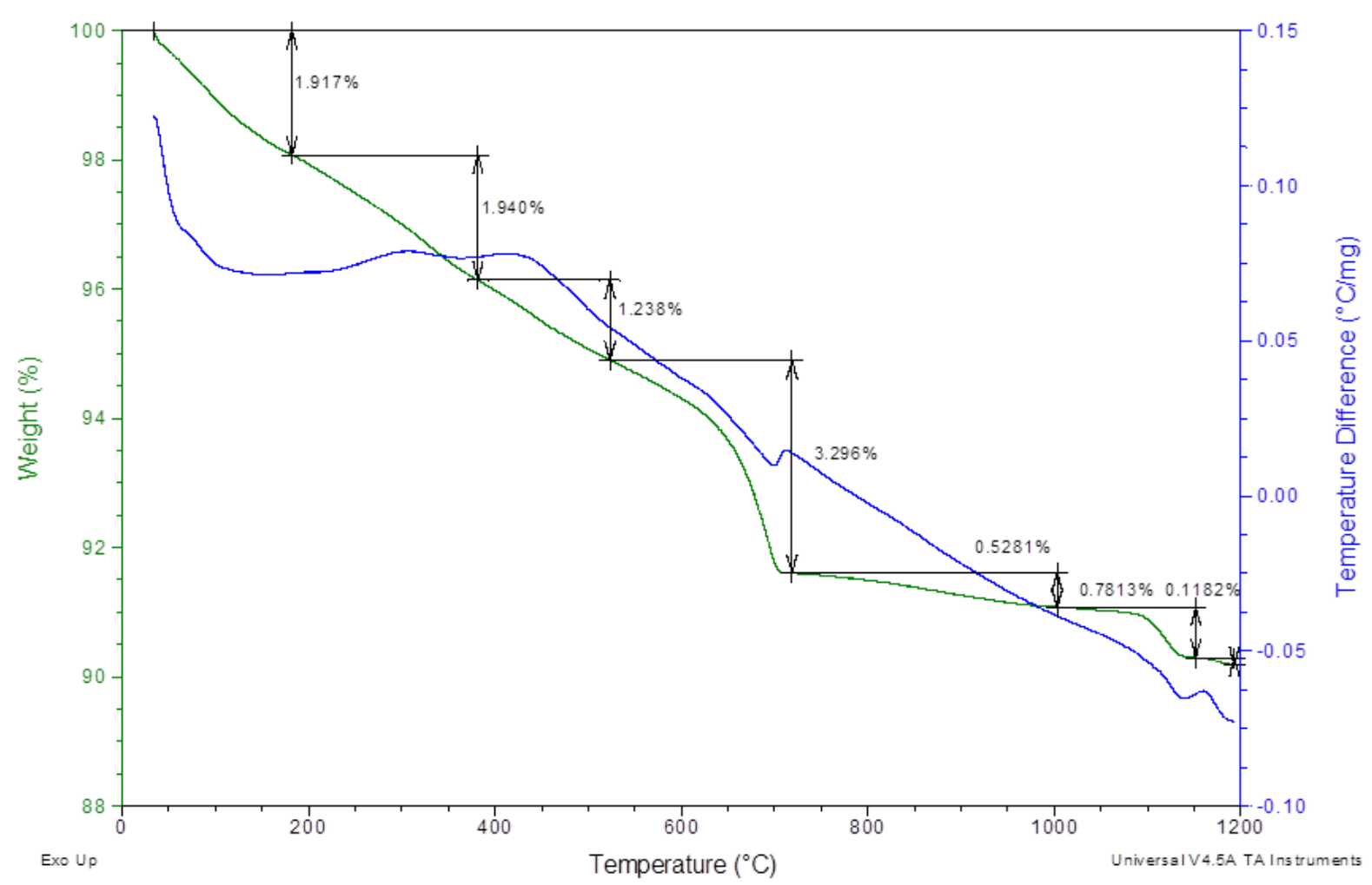

Fig. 1. 
1

2

3

4

5

6

7

8

9
10

11

12

13

14

15

16

17

18

19

20

21

22

23

24

25

26

27

28

29

30

31

32

33

34

35

36

37

38

39

40

41

42

43

44

45

46

47

48

49

50

51

52

53

54

55

56

57

58

59

60

61

62

63

64

65

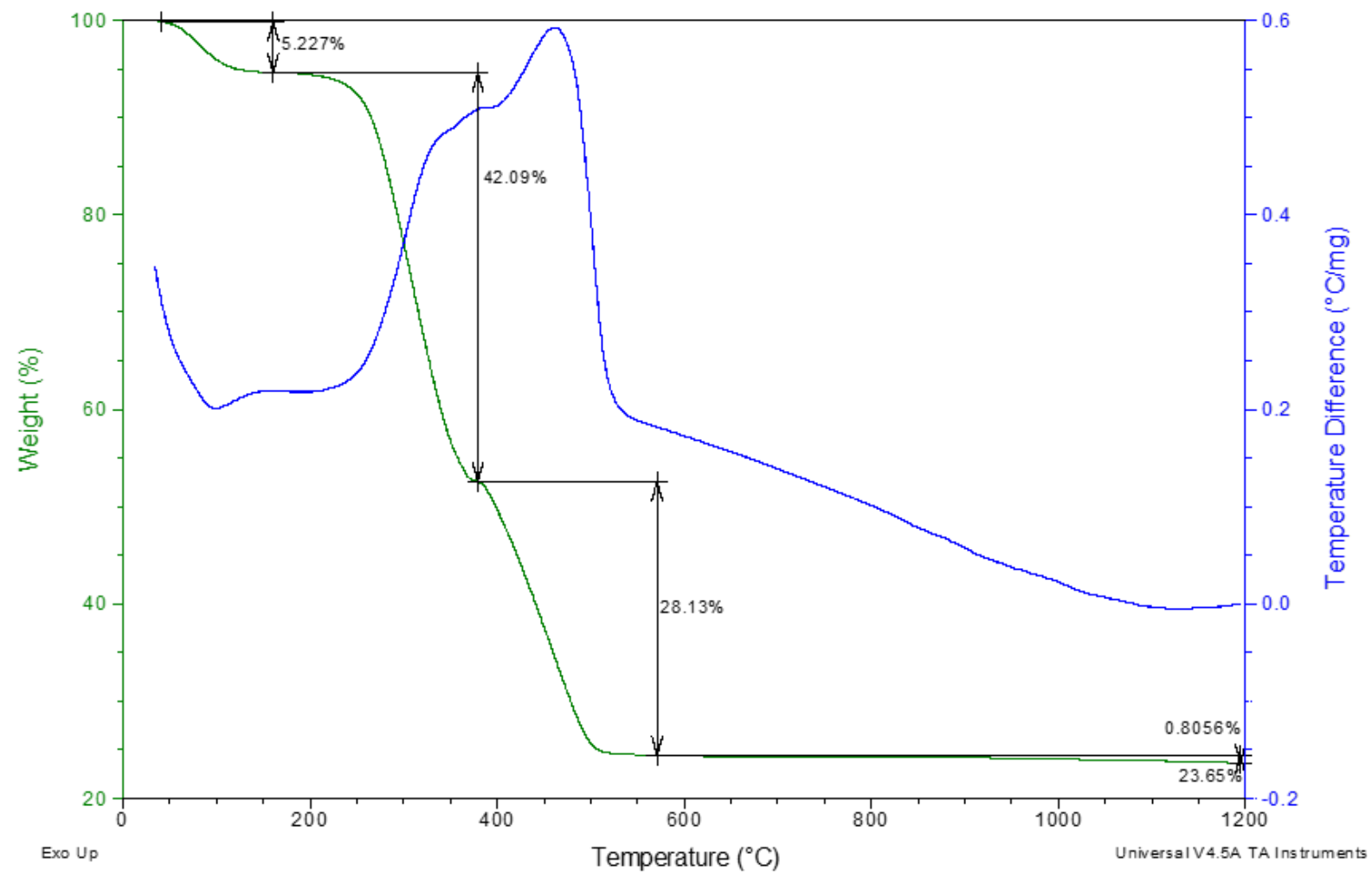

Fig. 2 


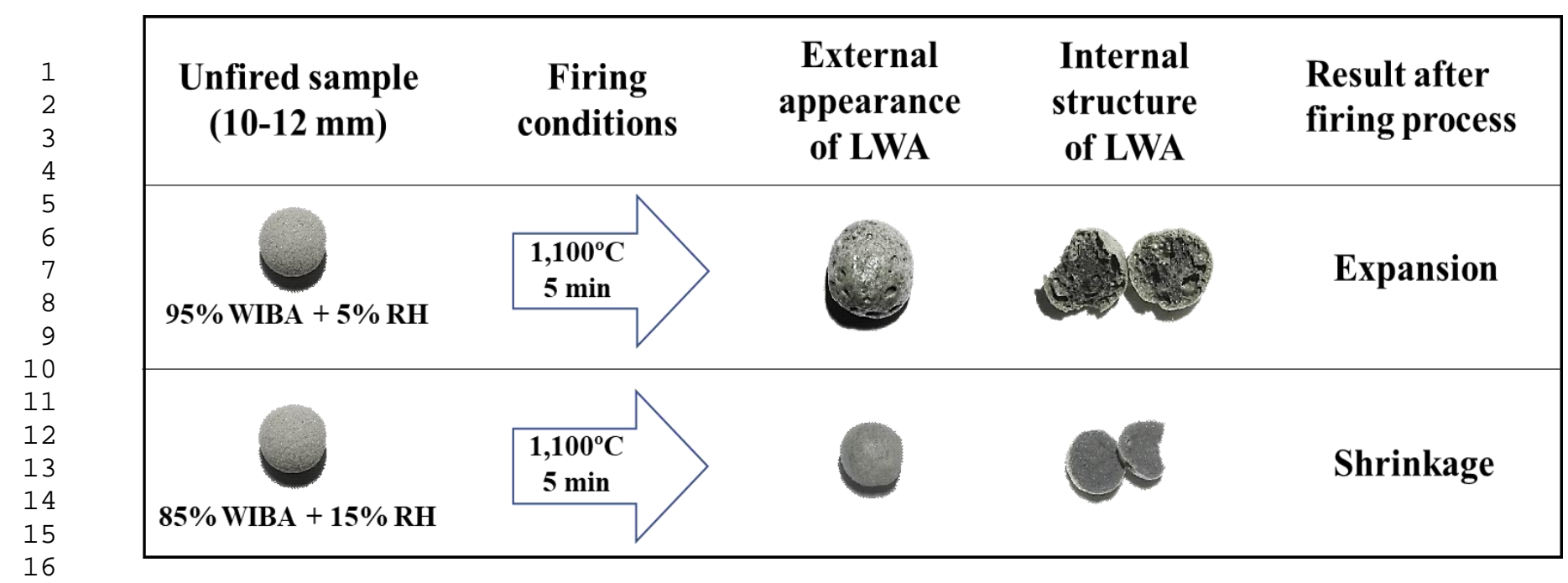

Fig. 3. 


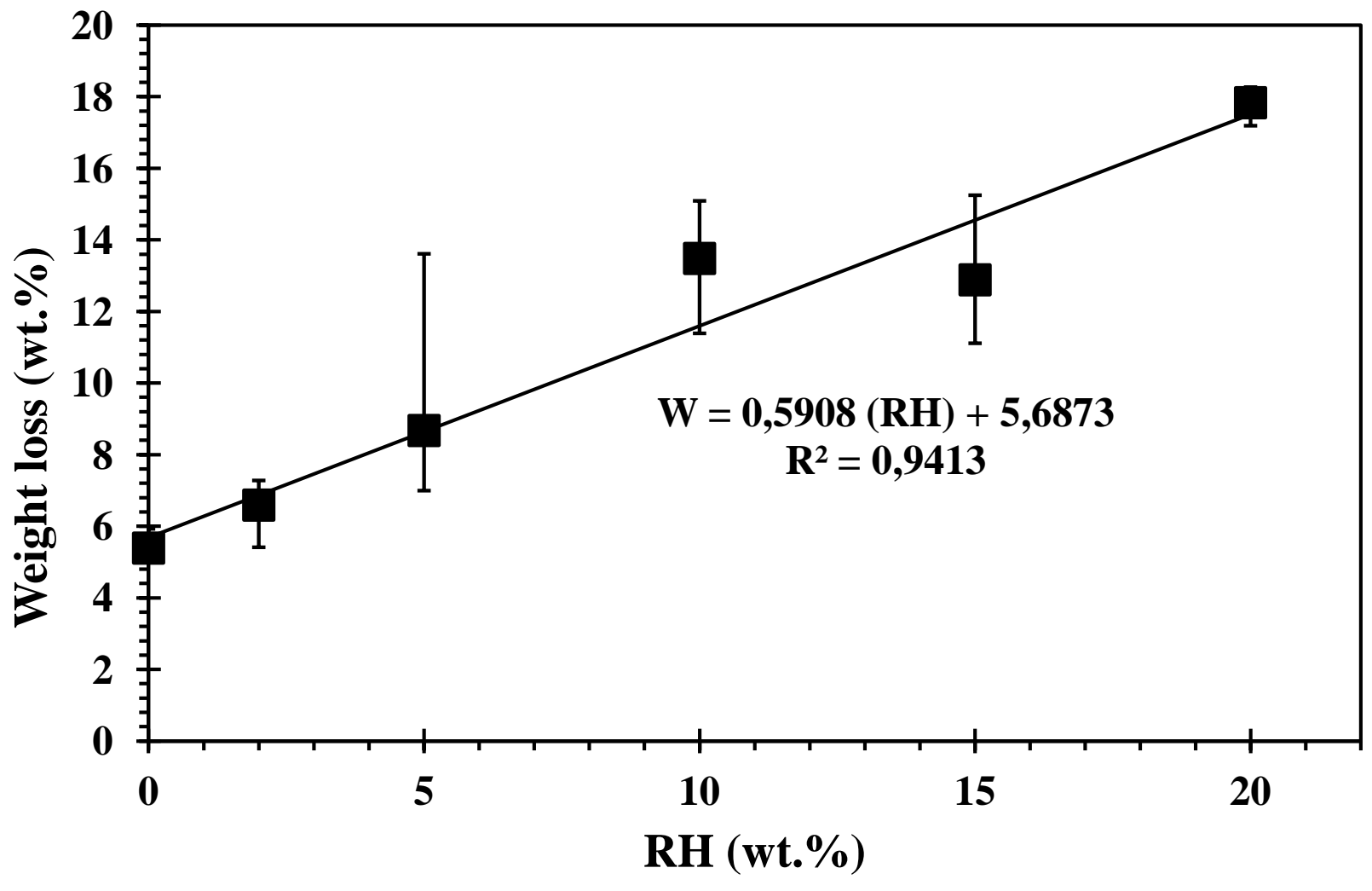

Fig. 4 

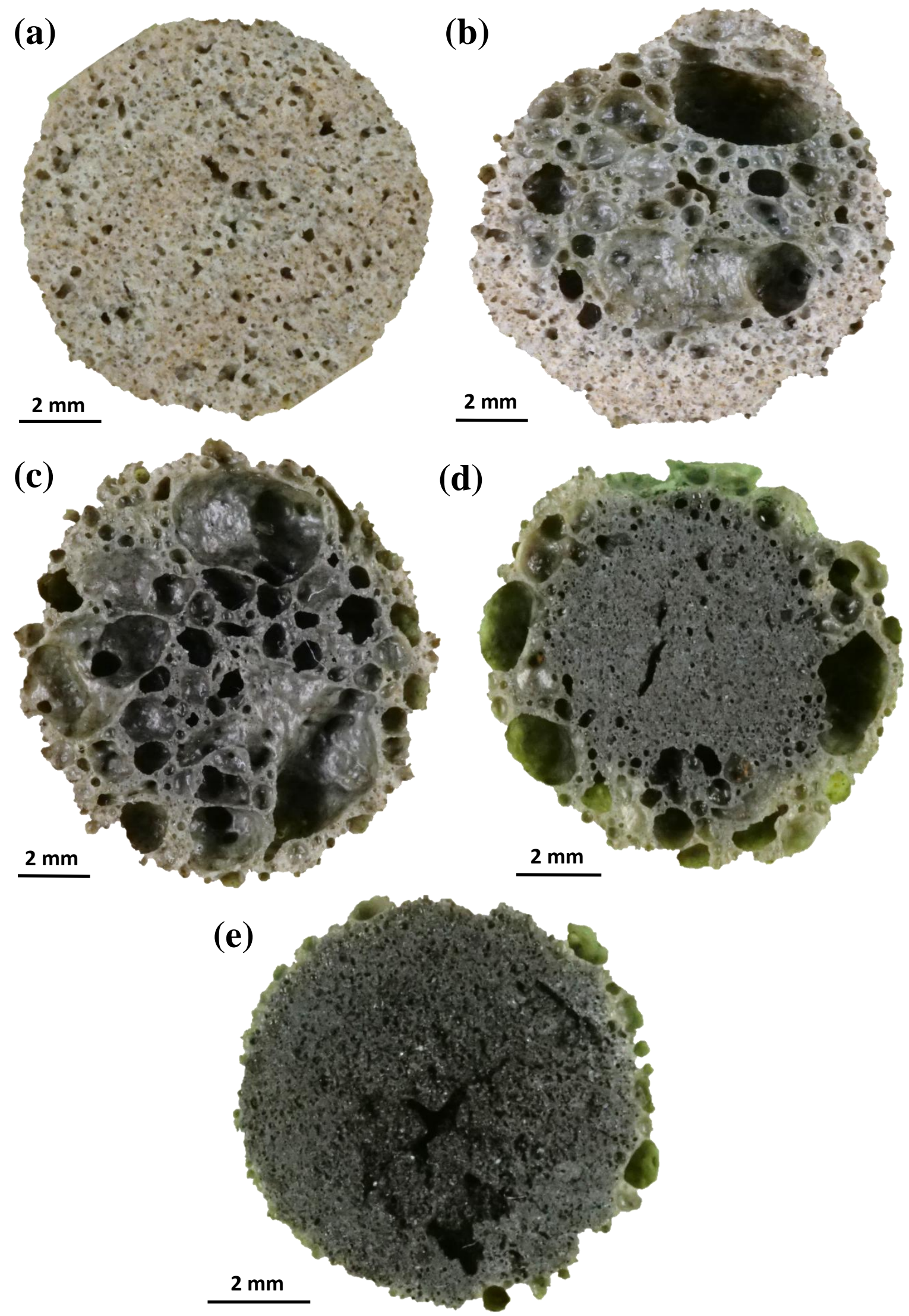

Fig. 5 

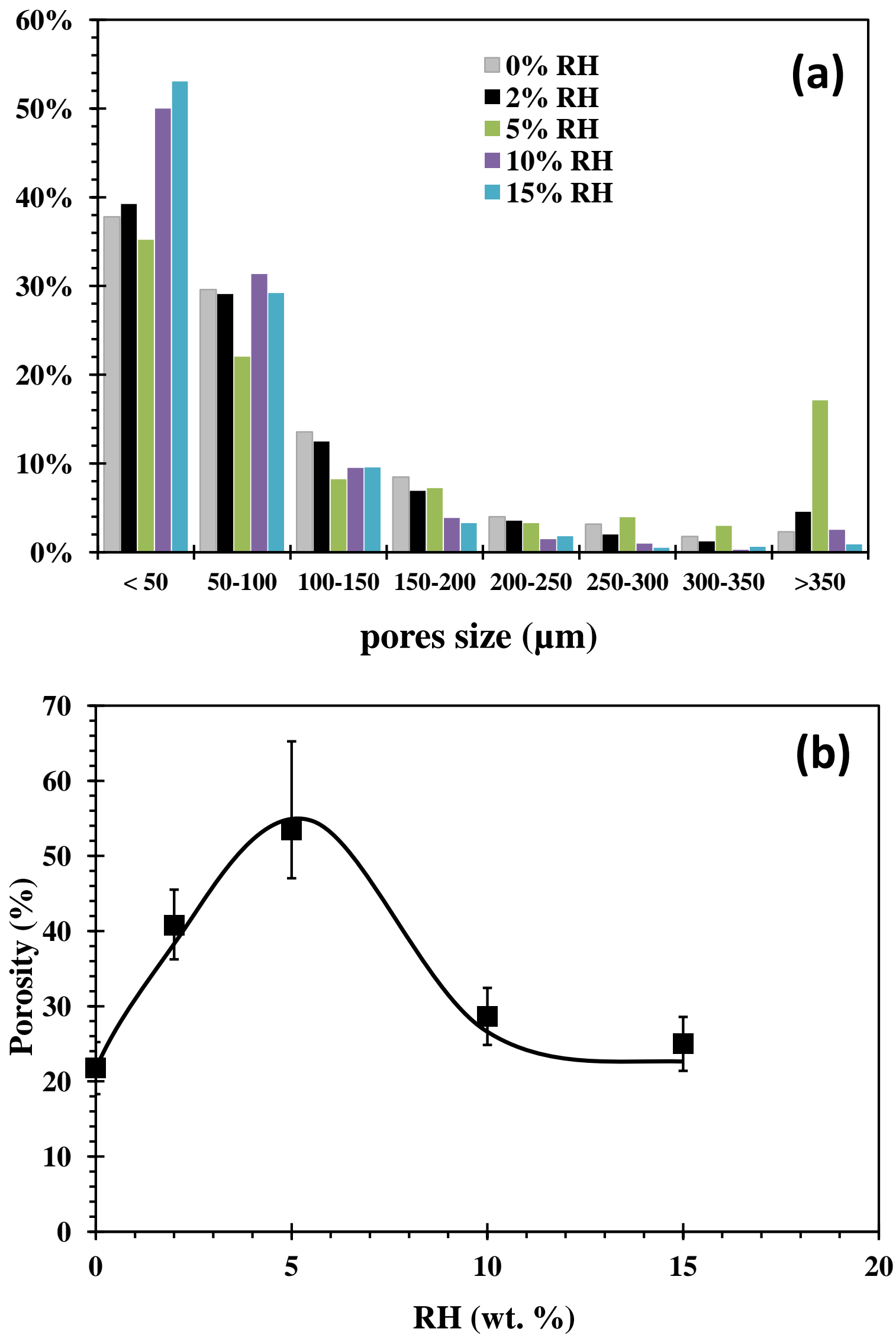

Fig. 6 


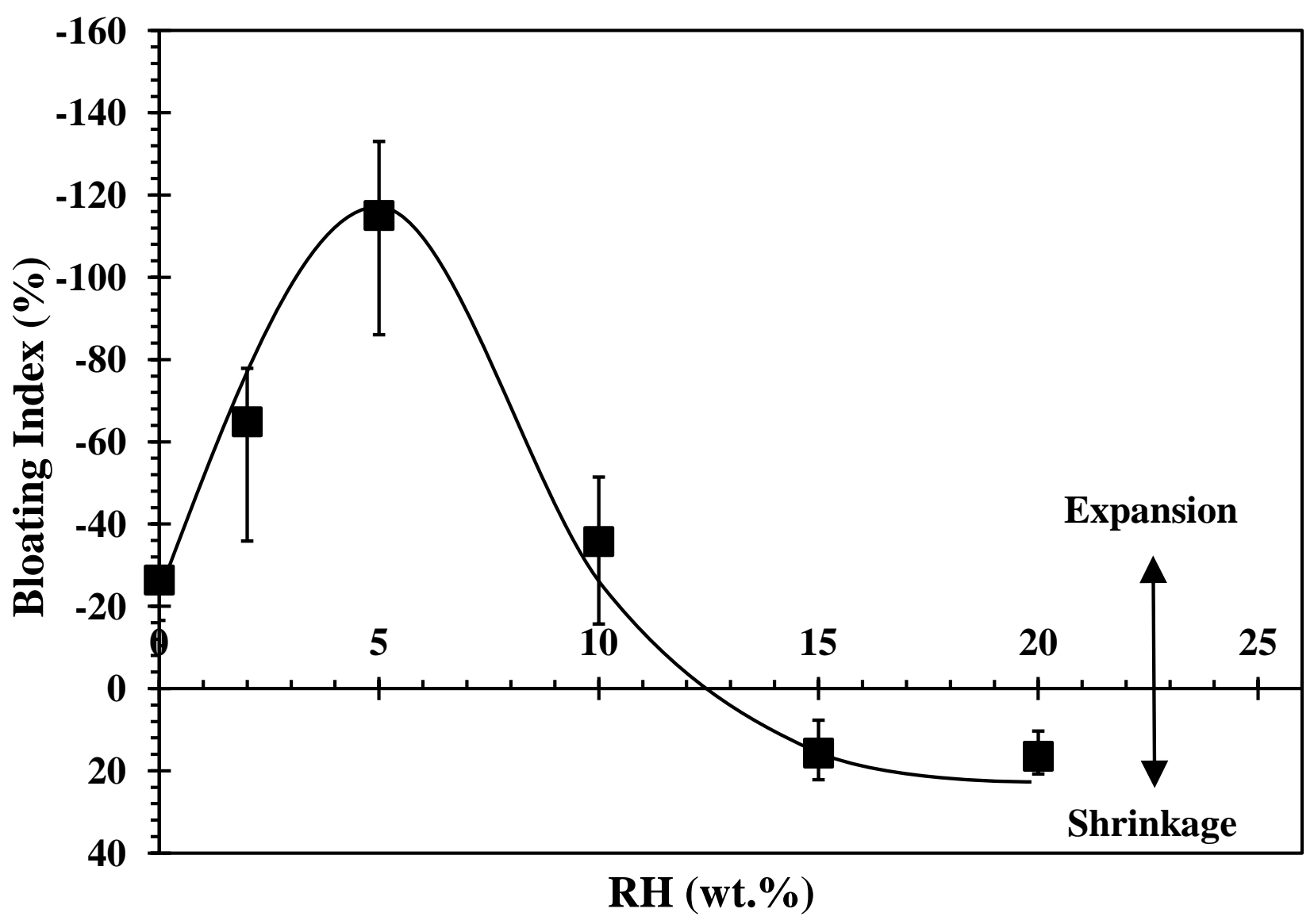

Fig. 7. 

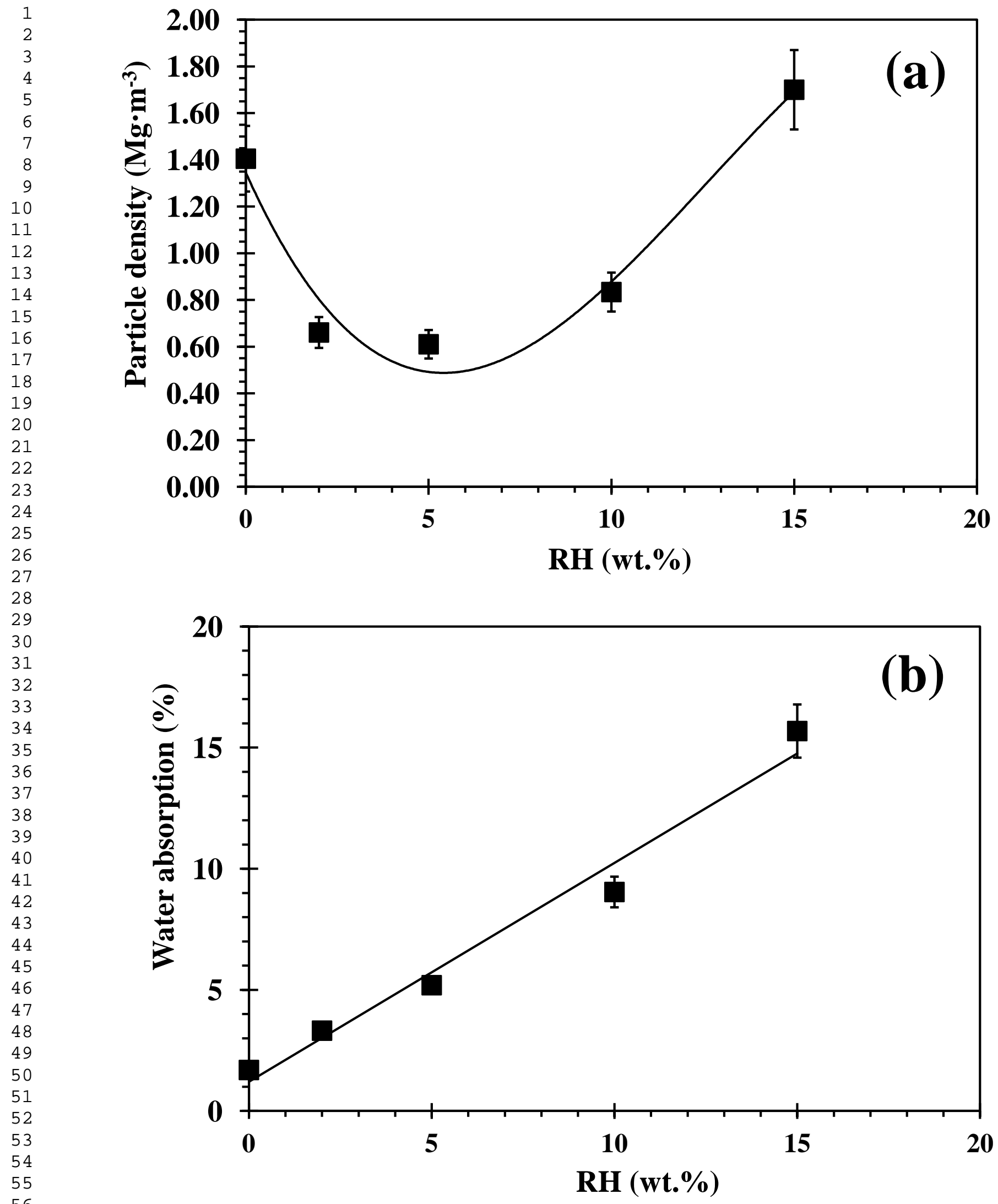

Fig. 8 


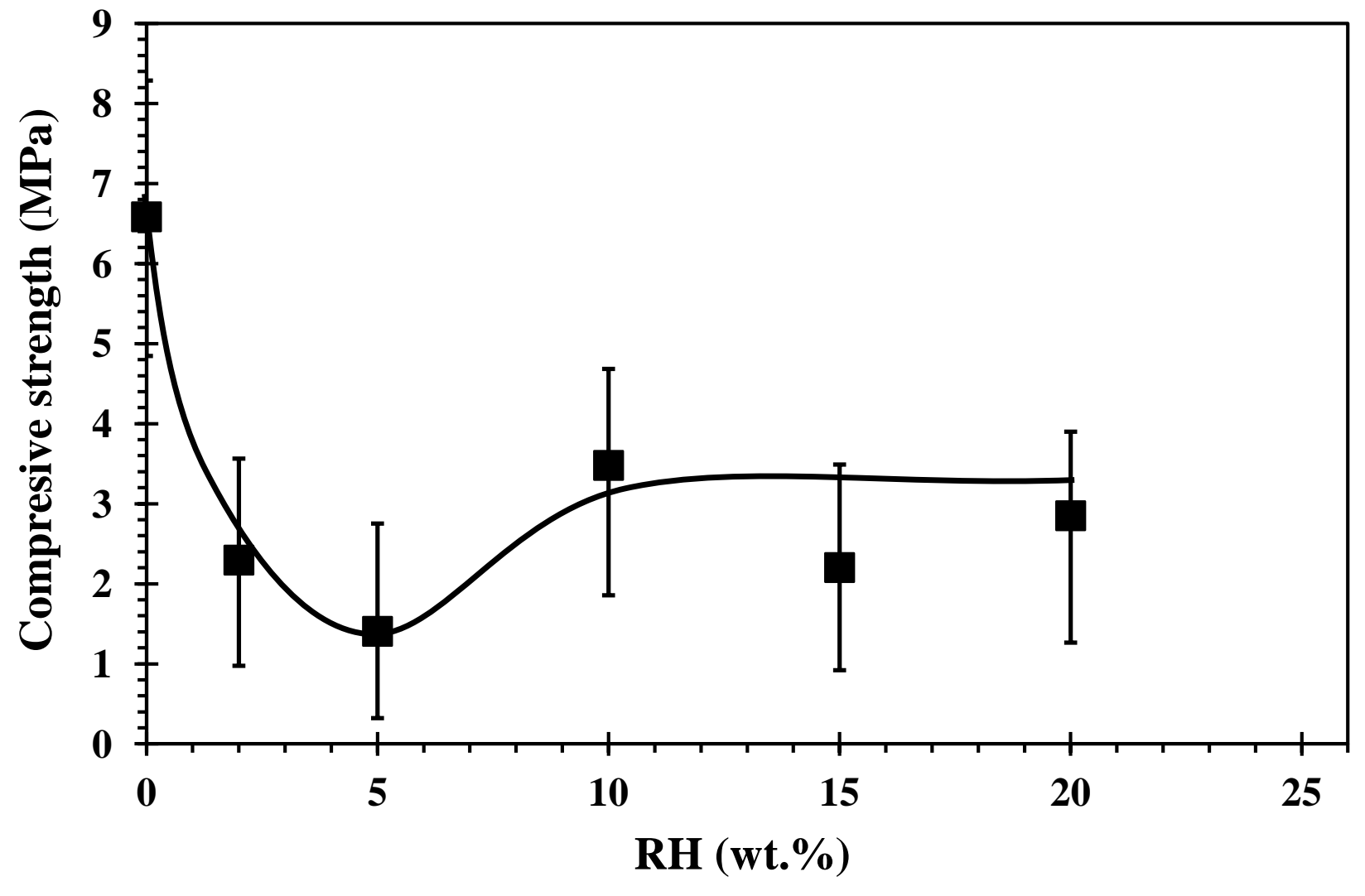

Fig. 9 